\title{
Infrared A-radiation alters the intracellular calciumhomeostasis in human dermal fibroblasts
}

\author{
F Macaluso*, C Calles, J Krutmann and P Schroeder
}

\begin{abstract}
Address: Instutit für umweltmedizinische Forschung, Molekulare Zellbiologie, Arbeitsgruppe Schroeder, Düsseldorf, Germany
\end{abstract}
* Corresponding author

from 12th Joint Meeting of the Signal Transduction Society (STS). Signal Transduction: Receptors, Mediators and Genes

Weimar, Germany. 29-31 October 2008

Published: 26 February 2009

Cell Communication and Signaling 2009, 7(Suppl I):A64 doi:I0.II86/1478-8IIX-7-SI-A64

This abstract is available from: http://www.biosignaling.com/content/7/SI/A64

(c) 2009 Macaluso et al; licensee BioMed Central Ltd.

Infrared-A radiation (IRA; 760-1440 nm), a major component of natural sunlight, accounts for one third of the energy reaching human skin. We have shown in previous studies that IRA irradiation of human dermal fibroblasts (HDF) leads to an increase in expression of matrix metalloproteinase 1 (MMP-1) via an increase in mitochondrial reactive oxygen species (ROS) and subsequent activation of the stress kinases ERK1/2.

The aim of this study was to elucidate which retrograde signaling pathways are induced by IRA. Microarray analysis of the IRA response revealed the regulation of several genes related to calcium homeostasis and this together with the known influence of mitochondrial impairment on cellular calcium fluxes prompted us to focus on the effect of IRA on the cellular calcium homeostasis.

Our results show for the first time that IRA irradiation $\left(100 \mathrm{~J} / \mathrm{cm}^{2}\right)$ of HDF leads to a biphasic increase of the cytosolic calcium level $([\mathrm{Ca} 2+] \mathrm{c})$ in the cell. Experiments utilizing EGTA to complex all extracellular calcium confirmed, that the source of the cytosolic calcium increase are intracellular calcium storages. We previously showed that IRA induced MMP-1 expression is dependent on reactive oxygen species (ROS), so we tested whether use of an antioxidant affects the IRA-induced increase of $[\mathrm{Ca} 2+] \mathrm{c}$. The treatment of HDF with N-acetyl-L-cystein (NAC) mitigates the IRA-induced rise in $[\mathrm{Ca} 2+] \mathrm{c}$. To address the question of functional relevance of the IRA-induced calcium flux for IRA-induced gene regulation, we treated the cells with the calcium chelator BAPTA-AM. The complexation of intracellular calcium lowers the IRA-induced increase of MMP-1 expression, demonstrating the involvement of calcium in IRA-induced signaling.

In conclusion, IRA irradiation leads to a ROS dependent calcium flux from intracellular storages into the cytosol. Interception of the calcium signaling by a calcium chelator affects the IRA induced gene regulation. 